\title{
Why Students are Cool to Internal Assessment? A study of the behavior of students of Koteshwar Multiple Campus (KMC)
}

-Dhruba Nepal ${ }^{1}$

\section{Abstract:}

Internal assessment is applied for learning achievement but it has been found that as the level of academic level and year increase, student's appearance in internal assessment shows declining trend. To find out the reasons, a small study based on qualitative data conducted. The underlying causes of cool behavior towards internal assessment is complacency to get through final examination instead of excelling, engagement with earning activities that mismatch with campus schedule teaching and assessment and girl students get married and pregnant as their age grow.

Key words:

internal assessment, drop out, causes of dropping internal assessment

\section{Background}

Internal assessment is one tool to invigorate learning process of a student. It is a tool used for assessing learning progress and giving feedback to students. It is assumed to serve as a stimulator for engaging him/her in learning endeavor. Though internal assessment is expected to play such an instrumental role in learning, it is not practiced by different universities in the same manner or enthusiasm. Even within one university, internal assessment provision is not practiced uniformly. Take the case of Tribhuvan University (TU), the largest one in Nepal in terms of student numbers and institutions (campuses and research wings), internal assessment is made an integral part of evaluation of learning of student to get through the semester for the academic courses run under semester system. Semester is normally half-year long while yearly system is one year long in terms of duration to complete the course by teaching/learning and examination. It means the courses run for one year go without formal mechanism of internal assessment to test learning progress and giving feedback to students. As a mechanism of regular monitoring of learning progress and feedback is considered indispensable element of formal education, of course, the missing of internal assessment as an integral part can be considered a 'loose nut and bolt' of the education system from the perspective of providing quality education. Though internal assessment is considered a good tool to improve educational quality because of frequent assessment of learning progress, TU had withdrawn semester and internal assessment

1 Lecturer of Management Stream, Koteshwar Multiple Campus, MPhil from Central Department of Public Administration, Tribhuvan University. 
system few decades ago (in the beginning of 2036 BS) under student's strong demand. Now again it is reviving gradually. Few technical and non-technical subjects like management have adopted semester system and internal assessment provision has been made as its integral part. Courses run under yearly system do not adopt internal assessment as mandatory or integral part. Even though internal assessment is not mandatory, some affiliated campuses of TU do practice internal assessment as terminal examination realizing its instrumental contribution to uplift education quality. Among the campuses affiliated with TU, Koteshwor Multiple Campus is one example of adopting terminal examinations. It conducts three such examinations. To motivate students in appearing in terminal examinations, it has adopted the provision that the score obtained in terminal examination as one mandatory provision for providing scholarship (by the Campus). Further, there is also a provision of slapping Rs 200 as a fine against not appearing in internal assessment of each subject.

\section{Problem statement and research question}

Realizing that internal assessment as an informal tool of enhancing learning quality by a growing number of universities and campuses are showing interest in adopting it as a part of academic activities. Despite having such noble reason of enhancing learning quality, it has been found that a significant number of students do not appear in internal assessment.

The Table 1 shows the number and percentage of students did not appear in internal assessment held in Asoj and Poush of 2073 (October 2016 and January 2017) BS by Koteshwar Multiple Campus. As per the Table, a glaring scene of wide difference in percentage of absentees in internal assessment is found - from 11.86 percent (Grade 11 in Hotel Management) to 89.56 percent $\left(4^{\text {th }}\right.$ Year of BBS).

On class observation, it has been found that as students reach to higher years (in the sense that $2^{\text {nd }}$ year is higher than $1^{\text {st }}$ year and $3^{\text {rd }}$ year is higher than $2^{\text {nd }}$ Year), there is a trend of declining number of students who regularly attend classes). The reasons are obvious, different reasons pull towards and push out students from the classrooms. Those reasons are: joining employment, unfavorable time schedule, marriage and its effect and so on. (These reasons are noted by asking the irregular and drop out students.)

Quality education is the concern of both students and campus authority, and internal assessment is applied for it, it has been found that there is a significant number or percent of absentee students out of almost regular students. This raises a question - why regular students do not appear in internal assessment/examination? Delving into this question would help to examine reasons and find out solution for making more students to appear in internal assessment.

No and percentage of students appeared in internal examination

First Internal Examination of Academic Year 2016 of Koteshwar Multiple Campus

\begin{tabular}{|l|l|l|l|l|l|l|l|l|}
\hline \multirow{2}{*}{ Level } & \multirow{2}{*}{ Faculty } & \multirow{2}{*}{$\begin{array}{l}\text { Enrolled } \\
\text { students }\end{array}$} & \multicolumn{2}{|l|}{$\begin{array}{l}\text { Appeared in } \\
\text { all subjects }\end{array}$} & \multicolumn{2}{l|}{$\begin{array}{l}\text { Partially } \\
\text { appeared }\end{array}$} & \multicolumn{2}{l|}{$\begin{array}{l}\text { Absent in all } \\
\text { subjects }\end{array}$} \\
\cline { 5 - 10 } & & & No & Percent & No & Percent & No & Percent \\
\hline
\end{tabular}




\begin{tabular}{|l|l|l|l|l|l|l|l|l|}
\hline 11 & Business & 170 & 93 & 54.71 & 47 & 27.65 & 30 & 17.65 \\
\hline 11 & Computer & 52 & 35 & 67.31 & 9 & 17.31 & 8 & 15.38 \\
\hline 11 & Hotel Management & 59 & 37 & 62.71 & 15 & 25.42 & 7 & 11.86 \\
\hline 12 & Business & 173 & 63 & 36.42 & 49 & 28.32 & 61 & 35.26 \\
\hline 12 & Hotel Management & 47 & 21 & 44.68 & 10 & 21.28 & 16 & 34.04 \\
\hline 12 & Humanities & 80 & 21 & 26.25 & 20 & 25.00 & 39 & 48.75 \\
\hline 12 & Education & 48 & 7 & 14.58 & 7 & 14.58 & 34 & 70.83 \\
\hline $3^{\text {rd }}$ Year & Education & 90 & 22 & 24.44 & 19 & 21.11 & 49 & 54.44 \\
\hline $3^{\text {rd }}$ year & Humanities & 79 & 11 & 13.92 & 8 & 10.12 & 60 & 75.95 \\
\hline $3^{\text {rd }}$ year & BBS & 247 & 31 & 12.55 & 23 & 9.31 & 185 & 74.89 \\
\hline $4^{\text {th }}$ Year & BBS & 182 & 17 & 9.34 & 2 & 1.10 & 163 & 89.56 \\
\hline $1^{\text {st }}$ Year & MBS & 10 & 6 & 60.00 & 1 & 10.00 & 3 & 30.00 \\
\hline
\end{tabular}

(Note: This Table does not include the data of all internal assessments conducted. The data includes scenario of first internal assessment.)

\section{Literature review}

To look into relevant literature bearing on research question, the researcher resorted to internet using search tool scholar.google.com and repository of research articles booksc.org. Relevant literature on internal assessment and dropping the classes and internal assessment researched in other countries, not in Nepal are found.

Internal assessment is meant for learning achievement. It is of two types - formative and summative. Formative is informal, used for feedback to both a student and a teacher to take corrective measures aimed to improve achievement. On other hand, summative assessment is formal for certification and accreditation of learning achievement (Tarasa, 2010)

Indicating the implication of dropping out education in the UK context, Markey writes:

Young people who drop out of post-compulsory education may have missed opportunities for acquiring skills in the labour market, via apprenticeships and government-sponsored training programmes. Consequently, dropouts may be forced into dead end jobs or unemployment, including long-term unemployment, all of which is likely to lead to lower lifetime earnings (Markey, 1988).

In Nepal, what is the real implication of educational dropping or lower educational achievement is not studied, however, above implications are also applies in Nepal as well because minimum qualification is set for a job and even merit prevails among candidates with the same educational qualification, dropping out any education pursuit results in lower income.

Based on the study conducted in UK, it was found distilling available existing literature on dropout behavior has the influence of personal, family, peer group, schooling, local labor market and prior attainment variables. In terms of prior attainment, more able individuals are most likely to stay on in education because the expected benefits are much higher and risks of failure (a cost) are lower (Bradley and Lenton, 2007). 


\section{Methodology}

To delve out the reasons of dropping of internal assessment, it ought to know the set of apparent and underlying reasons behind it. Taking into account the above literature in mind, the behavior of students to pursue internal assessment as formative purpose, this small study has been conducted. As the study conducted in the context different from ours, it may not apply very exactly with us because in social science, context matters significantly, this study is undertaken in the Nepali context, even in the campus where most of the students belonging to lower middle and low socio-economic status join the campus.

For such study, this researcher thought that inductive reasoning would be appropriate because it creates an inference to make theory. Though the study itself small sample of respondents, it is expected that it highlights few indispensable reasons related with dropping of internal assessment prevalent in the context of community campuses.

To know the reasons, interview with sample students who dropped the internal examination conducted following basic method suggested by grounded theory as a research method.

\section{Data collection and analysis}

From data collected through interview following information received and analyzed.

\subsection{Could not prepare satisfactorily}

On asking a question why s/he did not appear in internal assessment, the answer remained - I could not prepare satisfactorily, so decided to drop the assessment. On further query that you were informed through the academic calendar and also through campus authority that when the assessment would hold, then also why did not you prepare for assessment, the answer was that could not manage time to prepare. On asking - whether s/he would drop the final examination on the same logic of no preparation could be done, the answer was "no", because at any rate it should be done, else one year would be delayed to complete the academic level.

From such an answer, it can be drawn that though a student gives reason of failing to prepare for internal assessment, the reason of not realizing the importance of internal assessment in contributing learning endeavor, rather feeling it as a burden.

\subsection{Busy in other priority work at that time}

Respondents also answered that $\mathrm{s} / \mathrm{he}$ had to do other priority work at that time, for example, parents called them home for certain reason. As most of the students are from outside valley, it could happen that parents called them. On asking further, would you have gone home if it was yearly examination was held, students answered no. It means, students do not give high emphasis on internal examination, and tell parents that during the period of internal examination, they are almost free, so knowing it that no important is happening during that period in their wards academic pursuit, so they called them home. Though apparently parents' insistence seems to be the reason of making students drop internal assessment, but in real 
sense, students themselves are the reason of not giving emphasis on it. Had they told parents internal assessment is an integral part of the academic pursuit the parents would not have asked them drop the test and run to home. The underlying reason thus is considering internal assessment not much important aspect of academic pursuit by students.

\subsection{Shifting priority}

\section{Graphic presentation of drop out students from internal assessment}

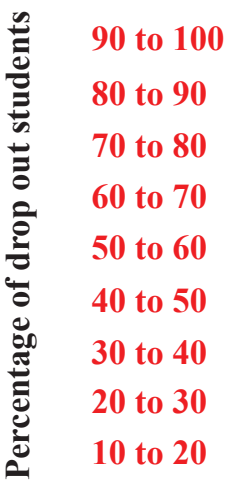

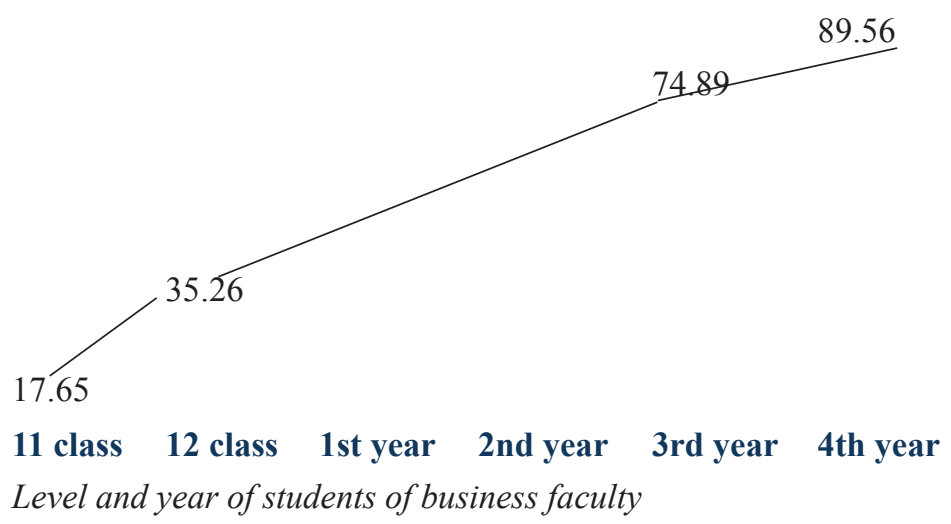

From interviewing the internal assessment drop out students, another reason also unfolded. That reason is as the age increases, a student needs to look for means to meet hand to mouth. Thus, few students have already joined job or have become self-employed. In that condition, students become more concerned to their earning vocation rather than study. For example, one student told that she has started own mushroom farm that demands her to go for marketing, thus cannot be regular in the class, even can attend assessment. However, she would continue the study by taking tuition classes. As campus class time does not fit with her need, she chooses time that fits her. Such kind of suitable time for her is tuition.

As the academic year goes up, students get gradually engaged in earning activity that may affect their previous priority on learning to earning, thus, they become irregular in classes or even totally drop academic pursuit. From data also, it can be triangulated. Above Table shows that students of Business faculty of 11 Class, the percent of dropping internal assessment is 17.65 whereas as they reach 12 Class, the percent increases to 35.26 . As it goes up to BBS $3^{\text {rd }}$ and $4^{\text {th }}$ Year, the percent increases steeply to 74.89 and 89.56 .

Such trend is discerned till bachelor level. As students reach to master degree, the trend is different. As in case of master level students of business faculty, this trend is different. As only 10 students are admitted MBS, the number itself is small and the trend is seen quite different, thus, this and other reasons may not be true with them. 


\section{Inference and conclusion}

The quantitative data show that there is a trend of dropping internal assessment by students as the level and year of academic class increases in Koteshwar Multiple Campus. The Campus has been practicing incentive and disincentive to encourage students to attend the assessment. Internal assessment is meant to contribute in enhancing education quality through self-realization and feedback mechanism. To make it attractive in financial terms as well, there is a mandatory provision of attending internal assessment to be eligible for scholarship that is provided through waiving partial and full tuition fee. To put disincentive for dropping internal assessment, the Campus even has been practicing to slap Rs 200 as fine per subject for dropping internal assessment. To inform students when such assessment will be held, academic calendar is given in the beginning of academic year. Despite having above incentive and disincentive provision, there is high ratio of dropping internal assessment that demands a study on why students are dropping it.

For the study, qualitative method followed. Students who dropped internal assessment were interviewed on personal basis.

From the interview, three major reasons delved out. First reason, students shy to appear in internal assessment if they do not satisfy with the preparation for the assessment. Second, students were engaged with other activities while internal assessments were held. Third, as the education level increases, students get engaged in earning activities, that demands their attention towards those activities and make them drop internal assessment.

Above are apparent reasons. But underlying reasons are not the same, but different. They are: First, low level of motivation to excel in academic pursuit is one reason. The students who join this Campus come from poor and low-middle economic background. Besides, their past academic performances were not also bright. That does not instill motivation to excel academically, rather to be contented with just getting through final examination. Such psychology creates a barrier in making all efforts required to do better academically. As internal assessment is not mandatory provision to pass final examination, students lose interest in academic excellence, that's clear indication is revealed in dropping out internal assessment. Second, again the socio-economic backgrounds of students push them to look for earning activities. In many cases, those activities mismatch with internal assessment, thus they choose to drop internal assessment. Third, it particularly applies to girl students. Such students get married and some become pregnant. That causes impediments in pursuing regular classes and even internal assessment.

\section{Works Cited:}

Bradley, Steve and Lenton, Pam (2007). Dropping out of post-compulsory education in the UK: an analysis of determinants, Journal of Polpular Economics 20 (2007): 299-328, doi 10.1007/s00148-006-0110-y

Markey JP (1988) The labor market problems of today's high school dropouts. Mon Labor Rev 111(6):36-43

Tarasa, Maddalena (2010). Assessment for learning: assessing the theory and evidence, Procedia Social and Behavioral Sciences 2 (2010) 3015-3022, doi:10.1016/j.sbspro.2010.03.457 